\title{
World TB Day 2010: Eradicating tuberculosis in sub- Saharan Africa needs effective and committed north-south partnerships
}

The World Health Organization (WHO) has designated 24 March of each year as 'World TB Day', to mark the anniversary of Robert Koch's discovery in 1882 of the cause of tuberculosis (TB), Mycobacterium tuberculosis. Regrettably, this is not a day for celebration. Instead, governments, policy makers, scientists and funders must reflect on the paradoxical fact that, although effective and cheap therapy has been available for over 60 years, TB kills nearly 1.8 million people every year, that is, 5000 people every day! Together with HIV / AIDS and malaria, TB remains one of the most important causes of death from infectious diseases worldwide. World TB Day provides an opportunity to reflect on the poor state of TB control globally, particularly in sub-Saharan African countries (SSA). ${ }^{1}$

The WHO, donor governments and other funding agencies have focused much of their investments over the past decade on TB control, with some measurable success. The WHO 2009 report $^{2}$ shows epidemiological evidence of a decrease in the number of new cases of TB in China and Asia, although the global TB disease burden remains unacceptably high. In particular, TB continues to spread relentlessly in high HIV endemic SSA, where the absolute number of TB cases continues to rise and TB remains the predominant cause of death among the HIV infected. Furthermore, the emergence of multidrugresistant and more ominously extensively drug-resistant (XDR) $\mathrm{TB}$ in SSA adds to the growing pressures on health systems and national TB programmes, while the recession causes financial hardships and compromises TB control efforts in developing countries. Creative ideas and pragmatic new strategies are urgently required if the TB epidemic in SSA is to be brought under control. Committed research and capacity development are central to this.

SAMJ Editor Professor Daniel J Ncayiyana stated in the BMJ that 'Africa's health challenges are not insurmountable and ... Africa must look for what South Africa's President Thabo Mbeki characterised as "African solutions to African health problems". ${ }^{3}$ Only when a critical mass of African researchers working on African soil has been restored will Africa generate new knowledge relevant to its most pressing health problems.' Since the 1950s, as African countries became independent, they embarked on developing their own medical schools and training programmes. Many African institutions have not been able to develop and sustain their research and development (R\&D) programmes to international standards, which has long been a subject of debate and discussion. ${ }^{4}$ This is an indictment of the former colonial powers for inadequately investing in African-led research and training programmes, of current Western funders and expatriate-led R\&D units in SSA, ${ }^{3,4}$ and of African governments for failing to support and prioritise local R\&D initiatives. SSA institutions have been plagued by lack of funding for R\&D and of proper infrastructures, financial mismanagement, and trained indigenous staff capable of independent local research. Furthermore, an ageing African scientific leadership has overlooked the important issue of inhouse mentoring for younger scientists.

$R \& D$ and training must be high on the agendas of donor agencies and African governments. ${ }^{5}$ The more developed African R\&D groups should get out of their bunkers and partner with less developed sites within Africa, to enhance African R\&D and networking. Unfortunately, project grant funding from funding agencies has failed in sustaining substantial African-led R\&D, owing to budgetary and time limits. In 2003 a timely new initiative, the European and Developing Countries Clinical Trials Partnership (EDCTP), was founded by the European Parliament and Council. ${ }^{6}$ It is a partnership of 14 European Union member states, Norway, Switzerland, and SSA countries, formed to fund acceleration of north-south partnerships on new clinical trial interventions (new or improved drugs, vaccines, diagnostics and microbicides) in SSA to combat HIV/AIDS, malaria and TB. ${ }^{7}$ The aim of integrating these activities is to develop the capacity to sustainably conduct clinical trials in SSA.

The initial jerky start of the EDCTP ${ }^{8}$ was strengthened by a new administration that transformed the EDCTP into an important funding body for research and capacity development in SSA countries, far surpassing that of traditional Western country funders of African R\&D. ${ }^{7}$ The EDCTP seeks to be synergistic with other funding bodies and hopes to foster true and lasting partnerships between European and southern African partners. The active involvement and contribution of African scientists may lead to joint ownership of the EDCTP programme with European counterparts. Strong commitment that moves beyond tokenism is required from African scientists to realise these aims. Correctly utilised, these initiatives should assist the development of regional networks of excellence in sub-Saharan Africa with sustainable R\&D programmes that should be supported by their local governments.

All funders of African R\&D must join hands with the EDCTP initiative to have a multiplier effect. Since the EDCTP has taken the lead in supporting the important and neglected areas of research and training in Africa, it is anticipated that all funding agencies similarly involved will align themselves synergistically with EDCTP initiatives. The UK Medical Research Council (MRC) is already involved with the EDCTP, and provision of MRC co-funding for some EDCTP grant calls appears encouraging, but MRC funds are insufficient to cover the increase in EDCTP activity. All 16 European countries involved in supporting the EDCTP must show their support and increase their co-funding of this novel initiative. The Wellcome Trust has recently joined the call to strengthen capacity for health research in Africa ${ }^{9}$ and plans to support African-led, UK-supported initiatives in training of African PhDs. ${ }^{10}$ It would be prudent for the innovative new strategy for Wellcome Trust Fellows' long-term support initiative also to be made available for African scientists. The Wellcome Trust 
should also consider providing flexible, long-term, auditable funding of existing African scientist-led consortia which could be commissioned to lead jointly defined and well-developed protocols on high-priority R\&D projects. Their results would improve health outcomes of adults and children in Africa.

Previously there was nothing to inspire and enthuse African scientists, and by default Western scientists continued to lead $R \& D$ as expatriates in Africa. The commitment by the EDCTP has now been translated into practice with 141 projects worth 255 million Euros already funded, mostly in the past 4 years. ${ }^{7}$ This involves 126 institutions in 28 sub-Saharan African countries and 43 institutions from 17 European countries and 51 other partners, a massive investment. These investments must be followed up by local governments assisting in establishing productive high-quality $R \& D$ programmes in SSA.

\section{Ben Marais}

Department of Paediatrics and Child Health

Tygerberg Children's Hospital and

Stellenbosch University

Tygerberg, W Cape

\section{Michael Hoelscher}

Department for Infectious Diseases and Tropical Medicine Klinikum of the University of Munich

Munich, Germany

\section{Peter Mwaba}

UNZA-UCLMS Research and Training Project University Teaching Hospital

Lusaka, Zambia

\section{Keertan Dheda}

Lung Institute

Department of Medicine

University of Cape Town and

Department of Infection

Centre for Infectious Diseases and International Health

University College London Medical School

London, UK

\section{Alimuddin Zumla}

UNZA-UCLMS Research and Training Project

University Teaching Hospital

Lusaka, and

Department of Infection

Centre for Infectious Diseases and International Health

University College London Medical School

Corresponding author:a.zumla@ucl.ac.uk
The stakes for African scientists and their governments have never been higher. Their real challenge remains - to translate the substantial EDCTP investment into deliverable and visible outputs of properly trained staff, improved and sustainable research infrastructures, effective R\&D networks, highquality research publications, and research output relevant to health policy. SSA countries should rise to this challenge, develop African scientist-led R\&D programmes and become internationally competitive, enabling them to develop their own solutions to their own health problems. ${ }^{3}$ We hope and trust that World TB Day 15 years from now will celebrate the turn of the tide against $\mathrm{TB}^{5}$ and other killer infectious diseases including malaria and HIV / AIDS, saving millions of lives and allowing future generations to realise their full potential.

Conflict of interest: All authors declare no conflict of interest.

References

1. Grange JM, Zumla A. Paradox of the global emergency of tuberculosis. Lancet 1999; 353: 996.

2. World Health Organization. Global Tuberculosis Control 2009 - Epidemiology, Strategy, Financing. WHO/HTM/TB/2009.411. Geneva: WHO, 2009.

3. Ncayiyana DJ. Africa can solve its own health problems. But first, the continent must reorder its priorities and commit to distributive justice. BMJ 2002; 324: 688-689.

4. Costello A, Zumla A. Moving to research partnerships in developing countries. BMJ 2000; 30; 321: 827-829

5. Zumla A, Mwaba P, Huggett J, Kapata N, Chanda D, Grange J. Reflections on the white plague. Lancet Infect Dis 2009; 9: 197-202.

6. Olliaro P, Smith PG. The European and developing countries clinical trials partnership. J HIV Ther 2002; 9(3): 53-56.

7. Mgone CS, Salami W. Editorial: EDCTP: a genuine north-south partnership. Trop Med Int Health 2009; 14(11): 1327-1328.

8. Editorial. Europe's clinical trials partnership programme in peril. Lancet 2007; 370: 362.

9. Wellcome Trust. African Institutions Initiative. Research capacity strengthening in Africa. 2009. http:// /www.wellcome.ac.uk/Funding/Biomedical-science/Grants/Other-initiatives/ WTD028338.htm (accessed 4 January 2010).

10. Whitworth JAG, Kowro G, Snewin V, Tanner M, Walport M, Sewankambo N. Strengthening capacity for health research in Africa. Lancet 2008; 372: 1590-1593. 